\title{
Urban Morphology of European and Asian Cities : A Descriptive Case Study
}

\author{
Ardy Maulidy Navastara ${ }^{1}$ \\ ${ }^{1}$ Urban and Regional Planning Department, Institut Teknologi Sepuluh Nopember, Indonesia \\ Email : ardy.navastara@urplan.its.ac.id
}

\begin{abstract}
According to Larkham (2002), urban morphology is an important assessment method in determining the transformation processes of urban contexture, making sense of the historical roots of spatial and functional structure and bringing them to the present day. The purpose of this study is to explore various urban forms in European and Asian cities from its morphological aspects, and construe the distinction between them. To be able construe them based on their city representatives from each continent (Europe and Asia), this study begins with a discussion toward the city of Rome and London as the representative of European city, and city of Singapore and Tokyo as the representative of Asian city. Exploratory approach is used for descriptive case study to deliberate decision in figure out the comparison between two urban form in European and Asian cities based on its morphological aspects. The result of this study shows that history, road patterns, and city's architecture strongly influence the morphological changes of the cities that discussed in this paper. Lastly, this paper also discuss the main comparation between european and asian cities based on the morphological characteristic.
\end{abstract}

Keyword : European and asian cities, urban form, urban morphology 


\section{INTRODUCTION}

Along with the continous cultivation in urban morphology studies which provides an analysis deals with the structure and/or pattern of a city, scientists had found out the morphological variety of cities and towns around the world as they reflects the periods in which they were formed and evolved. According to Larkham (2002), urban morphology is an important assessment method in determining the transformation processes of urban contexture, making sense of the historical roots of spatial and functional structure and bringing them to the present day. Meanwhile, Conzen (1960) states that the crucial part of urban contexture is the town plan, which comprises three distinct complexes of plan "plan elements": streets and their arrangement in a street system, plots and their aggregation in street blocks, and buildings. Refers to both Larkham (2002) and Conzen (1960) excerption, it becomes rellevant if the study of urban morphology that already examines in most of part of the world will not be separated from discussion of the history of its city, the pattern of the formation of road network system, and its architectural style.

The purpose of this study is to explore various urban forms in European and Asian cities from its morphological aspects, and construe the distinction between them. To be able construe them based on their city representatives from each continent (Europe and Asia), this study begins with a discussion toward the city of Rome and London as the representative of European city, and city of Singapore and Tokyo as the representative of Asian city, which we believe those cities is the basic way to group the sample continent both Europe and Asia. The urban forms are studied from development history, patterns of urban street network, and architectural style, as the underlying arguments based on larkham (2002) and Conzen (1960) that already been disscused before. Furthermore, the unique interpretation from the discussion will be the main consideration to stack up each of their urban form characteristics, and conclude what is the major difference among them.

\section{METHODS}

Given that the objective is to use the results from a discussion toward urban form beetwen European and Asian city to develop the distinction urban form among them, the case study method described by Yin (2003) is adopted as the most appropriate research methodology. Yin (2003) decribes three types of case studies; explanatory, exploratory and descriptive. In this study context, exploratory approach is used for descriptive case study to deliberate decision in figure out the comparison between two urban form in European and Asian cities based on its morphological aspects. According to Alasuutari (1993), exploratory case study divided in to two phases which are : (1) Simplification of observation, and (2) Interpretation of result. In the simplification phase, this study begin with explainning the urban form beetwen European and Asian city, while the interpretation of result phase will discuss the comparison beetwen them. Secondary data were adopted from literatures, and journals to gain insight about urban morphology in Europe and Asia.

\section{RESULTS AND DISCUSSION}

\section{Urban Morphology Of European Cities}

a. The Monarchy of Rome and London's Fluctuated Development

Beginning in the eighth century

B.C., Ancient Rome grew from a small town on central Italy's Tiber River into an empire that at its peak encompassed most of continental Europe, Britain, much of western Asia, northern Africa and the Mediterranean islands. Rome has become the capital city of Italy for centuries and also the oldest continuously occupied sites in Europe. Rome had been applied 
monarchy system of government until it ended in 509 B.C and turned into a republic. The classic city of Rome was showed by ancient buildings are still exsist such as Colloseum, Pantheon, and Arch of Constantine that also become one of tourist attraction in Rome. The ancient buildings of Rome have historical and art value. Culture and power influence were the main factors of the development of ancient buildings such as Arch of Constantine which was a monument built in 316 B.C. to celebrating the victory of Caisar Constantine.

Meanwhile, London has been a settlement for two millennia since it was founded by the Romans in the 1st century by the name of Londinium. In the 43 century BC the Romans invaded and colonized the city by bringing 40rb troops. This roman nation to build the civilization of the city of London. In 60 BC the Roman queen of the English attack led to a counter-attack that destroyed the city of London. One of the important part of London's urban history is the major fire that occured in 1666 for 5 days. The fire ruined the city of London area of 400 acres. The great fire has become the milestone in London's urban renewal, where Christoper Wern and Evelyn John came up with their idea about "rebuild London".

At the 17-18th centuries the London economy was growing rapidly, the number of people in that century reached 1 million as the result of London imperial power. The increase of London's economic also caused by port and trade which developed rapidly. London's early economy around 1845, largely based on light industry on commerce in agricultural sector. By 1880, London was a prosperous and burgeoning city due to the massive increase in immigration and a boom in manufacturing sector. London also experienced another economic boom in the 1920.

London and Rome's history has influenced the development of both cities in particular way. In Rome, several important ancient buildings were developed as the result of power influence by the monarchy system. Whilst London's milestone history also revelas how the city develop into one of world's biggest city.

\section{b. Road Patterns}

Grid pattern was used in ancient Roman period. The first road built was the Capitol Hill which connected Rome to its empire. Nowadays the structure of Rome is circled at a distance of about 6 miles from the capitol, by the ring-road. Rome had spanded for more than two and a half thousand years, starting from 753 B.C, causing inhabitant and settlements to grew fast. This city become the most populated comune and the fourth most populated city in the European Union. Since the settlers are in tremendous number, the governor has to provided road which connects the settlements to the central business distric. Furthermore, the city also provided access that integrated the historical sites due to the increase number of tourists. To simplify the comute, Rome has a massive transportation mode such as main railway station or Termini. The transportation mode is known for the most heavily used in Italy, around 400 thousand travellers passing through everyday, making Rome much easier to be reached from anywhere.

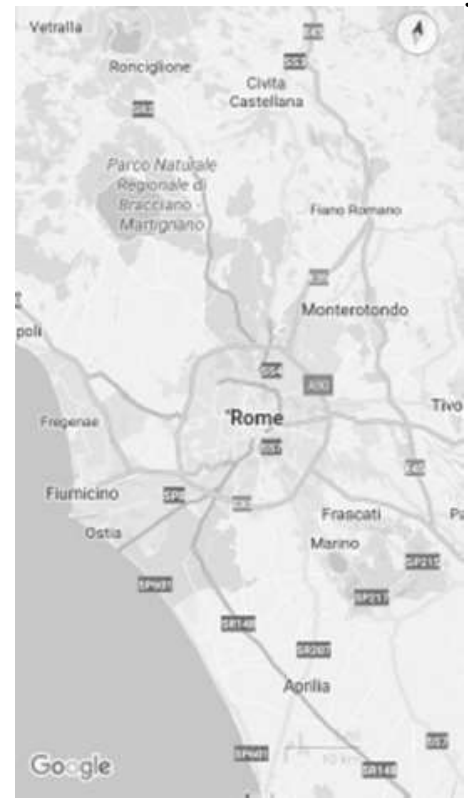

Fig. 1 Rome's Morphological from The Satelite 
Rome port, capital city of Roman was built with the appearance of two major highways, namely Cardo and Decumanus as the icon port's plan. Cardo and Decumanus were the main road that crossed to the direction of North to South and West to East that built along the building and monument in this port. That building was the main building for the government. The construction of this road gave a lot of advantage to Roman. This road decreased traffic jam in the central building of the government because it was twice a big as the other road.

London's street system has successfully supported by several different modes of transportation throughout its history. Created as a system for circulation, it has been able to adjust to changes in culture and technology after innovations to transportation were applied to central London.

Massive urban development has influenced the road patterns of both cities. Rome and London has been experienced the tremendous number of inhabitat growth that forced the city to expand the transportation system in order to fulfill the demand.

\section{c. Architectural}

Architectural characteristic of Rome strongly influenced by the Roman culture. In Rome, many buildings placed emphasis on symmetrically every elements in the building,balance construction, and a
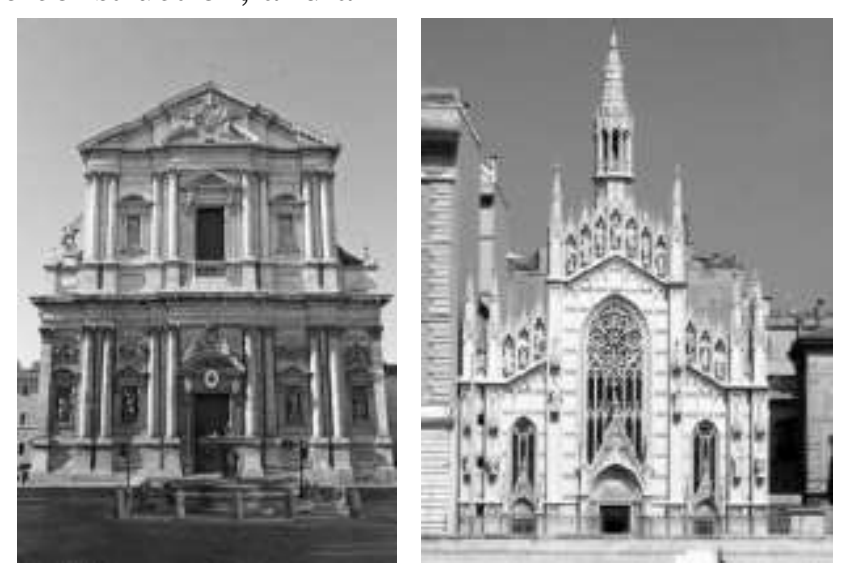

Fig.2 Symmetrical Architecture Buildings : Sant'Andrea (Left) and Sacro Cuore del Suffragio (Right). Fought Against Colonialism

\section{History of Tokyo}

very clear line. Arch construction, rows of windows that equipped with an arch above it, is the tipical of the building face architecture in Rome. Usually the arch werecombined with pillars and applied inside the building. The other architectural characteristics of Rome's buildings are cuba (domed roof), and building column.

London's buildings are too diversed to be characterised by any particular architectural style due to their varying ages. The buildings of Roman style were hardly exist as the result of the great fire in 1666. Some buildings from the Roman period that still remains after the great fire is the Tower of London and few scattered tudor survirors in the city.

\section{Urban Morphology Of Asian Cities}

a. The History Of Tokyo Who Rose From Destruction, And Singapore Who

\section{Early History of Tokyo (1923-1980)}

The history of Tokyo started 400 years ago. Originally named Edo, the city started to flourish after Tokugawa Ieyasu established the Tokugawa Shogunate here in 1603. Edo grew into a huge city with a population of over a million by the mideighteenth century as it was the center of politics and culture in Japan. The Edo Period lasted for nearly 260 years until Meiji Restoration in 1868, when 
Tokugawa Shogunate ended and imperial rule was restored. The Emperor moved to Edo, which was renamed Tokyo. Thus, Tokyo became the capital of Japan. Then, during the Taisho era (1912-1926), the number of people working in cities increased, and a growing proportion of citizens began to lead consumer lifestyles. Performing arts such as theater and opera thrived.

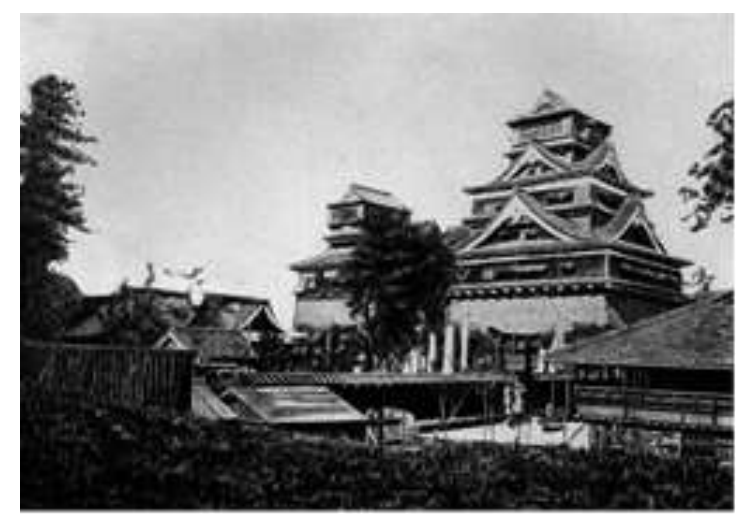

Fig. 3 Japan under the Shogun Source: Google Image

Tragedy that Changed Urban Form of Tokyo (1923-1980)

But, the actual starting point of development that influence the Tokyo urban form begins In September 1923, when Tokyo was devastated by the Great Kanto Earthquake. Over 140,000 people were reported dead or missing, and 300,000 houses were destroyed. Tokyo perforced to rebuilt it's city the total destruction. After the earthquake, a city reconstruction plan was formulated, but since the projected costs exceeded the national budget, only a small part of it was realized.

Shortly after the Great Kanto Earthquake, the Showa era (1926-1989) started in a mood of gloom. Even so, Japan's first subway line was opened between Asakusa and Ueno in 1927, and in 1928 the 16th general elections for the
House of Representatives of the Diet were held for the first time following the enactment of universal male suffrage. In 1931 Tokyo Airport was completed at Haneda, and in 1941 the Port of Tokyo was opened. By 1935 the resident population of Tokyo had grown to 6,36 million, comparable to the populations of New York and London.

\section{In the Face of Tokyo Metropolitan Government (1980-Now)}

In the 1980s, Tokyo took large steps in economic growth as a result of its increasingly global economic activity and the emergence of the information society. Tokyo became one of the world's most active major cities, boasting attractions such as cutting-edge technology, information, culture, and fashion, as well as a high level of public safety. From 1986 onwards, land and stock prices spiraled upwards, a phenomenon known as the "bubble economy."

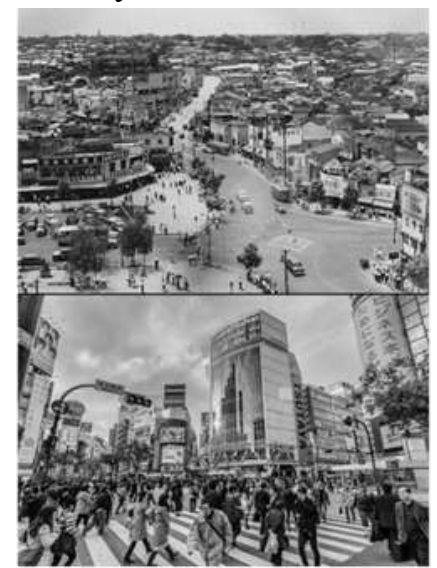

Fig. 4 Shibuya Crossing in Tokyo then (above) and present (below)

Tokyo's population is projected to start declining once it reaches its peak in 2020. Also taking into consideration changes to the structure of society such as the graying of the population, the Tokyo Metropolitan Government is pushing toward its goal of becoming the world's best city where a balance between 
economic affluence and the quality of life is achieved and anyone can fully enjoy life.

\section{History of Singapore}

Early Development Of Modern Singapore - Colonized for more than a Century (1819-1965)

Singapore urban development can not be separated from the fact that this country inhabited by many race and ethnicity in the past centuries. Culture that has been attached along with the tribes that once occupied singapur has an important role in the formation of morphology of the city. The culture that The arrival of Raffles marks a turning point in Singapore history. Singapore local residents signed an agreement stating that the British would be allowed to establish a trading post, in return for protection. In 1824 the British acquired full sovereignty over the island. Singapore became a British colony. In this era, Singapores growing rapidly due to its status as a free port. Arab merchants, Tiong Hoa and India made their stopover place. Then, On December 8, 1941, Japanese army landed in Kota Bharu, Kelantan. After two days the Japanese armies landed. Japanese soldiers continued to move throughout the Tanah Melayu causing British armies were forced to retreat south to Singapore. Ahead of January 31, 1942, 55 days after the onset of the attack the Japanese army, the Japanese army had managed to control the whole Tanah Melayu and get ready to attack Singapore.The fall of Singapore was the largest surrender of British defeat in history. Singapore was occupied by Japan from 1942 to 1945. On 16 September 1963, the British agreed to hand over Singapore, Sabah and Sarawak to join Malay Alliance so the Federation of Malaysia can be established. After discharge from
Malaysia, in 1965 Singapore began to emerge as a world trading power, as we known as the "Republic of Singapore".

b. Patterns of urban street network in Tokyo and Singapore

Order Unit of Smallest Community (Machi) As The Component Of Shaping Urban Street Network In Tokyo

The pattern of community organizations in Japan as a whole adopts nesting in the form of machi as the smallest unit. Machi consists of a set of families in which there are a collection of individuals. Thus the Japanese cities is actually the aggregation of a bunch machi.Within machi each household unit will automatically become members of an association called chonakaimachi.

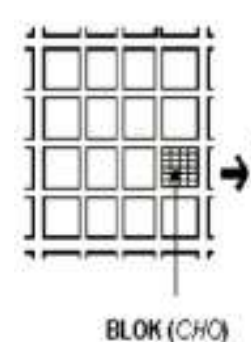

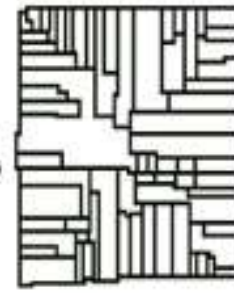

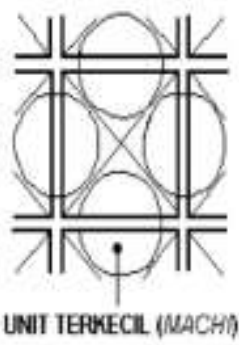

UNII TEPKECZL (NACH)
Fig. 5 The distribution system of Machi, Kyoto Source: Toshi Design is no Syuhou, 1998

The roots of this organization can be traced back to the Tokugawa era in the seventeenth century, when the authorities set up a control system called goningomi or group of five people. With this system, all five members of the group will work together with each other at the same time carry the same responsibility. When one member of a criminal involved the other four members have to bear the consequences anyway. This system allows the authorities to apply the rules that they create and build a spirit of mutual cooperation among the group members. 


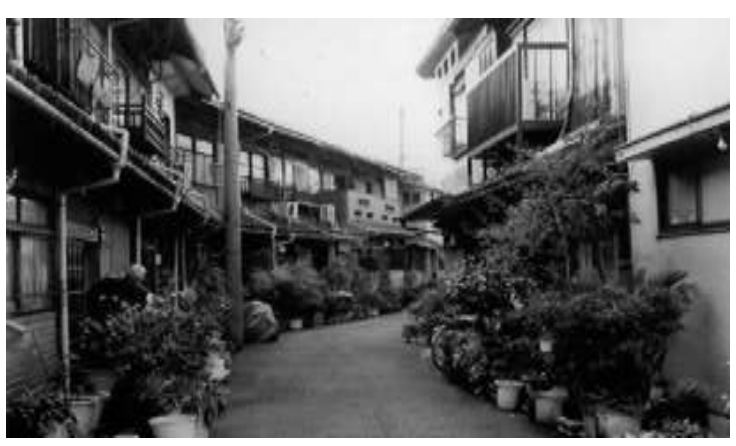

Fig.6 Machiya and Nagaya, Kyoto Source: Google Image

Space, Landuse Patterns, and Transportation Systems that formed Urban Structure in Tokyo

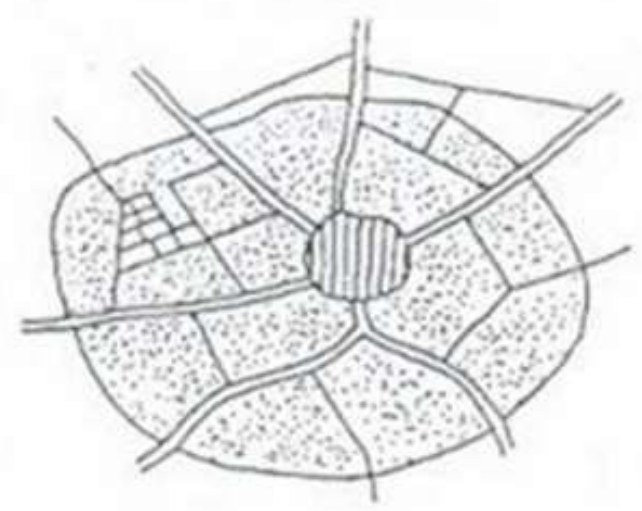

Fig.7 Urban Space Structure of Tokyo

The space structure which involves a series of several elements interrelated and influence each other. The elements relating to space structure are land use patterns, transportation, system and hierarchy of the city, as well as the carrying capacity of the environment. Tokyo is a city that has shaped of concentric space structure; all the activity and concentration density is in the center of town. In Tokyo, most of the facilities such as political, economic, cultural and academic facilities is located in the city center. Thats why, Tokyo ends up with a complex mass transit system and it is known for its busy hours. The transportation is railway mode. Everyone who wants to travel, they must travel by train. In addition, the streets in the city of Tokyo are also having narrow road width. This is because the urban structure has been built when the movements of people still rely on horse, chariot, or on foot. The transportation system in Tokyo follows the existed urban structure development.

\section{Urban Form in Singapore as a Reflection of Diversity}

As discussed in Singapore history, the variety of nations and tribes has an important role in the formation of morphology of the city. Urban form and structure in Singapore formed by the grid pattern structuring impact on the orientation of the façade architecture building With the pattern axis road axis which is divided by the building neighborhood landmark, such as Sultan Mosque and the Sultan Palace. In general, the buildings contained in this region was established with the form (Row Building), adopted many took home building typology from the Middle East, India, Europe to the Malay style in the 1900s. Furthermore, in Singapore the variation in building height, volume, and the way in which buildings are grouped together contributes to the unique character of specific areas. That phenomenon called as "Building forms". Building forms are guided by specific uses of buildings. As they have an impact on the streetscape, it is important that their forms respond to their surroundings.

\section{b. Architectural}

\section{From Traditional to Modern Mix-Culture} Architectural Style

In Japan's architecture is traditionally characterized by wooden structures, building forms the stage, with a roof tile ground straw. The hallmark of the 
door sliding system with Japan or sliding (fusuma) which allows the configuration of the internal space for tailored to different occasions. Since the 19th century, the architecture of Japan has incorporated elements of Western architecture, and it is currently become references in architectural design and cutting-edge technology. According to Bognar (1991), plenty of works of Japan's modern architecture put forward a more poetic inspiration and override scientific logic in solving design problems. In addition, most of Japanese use the phenomenology of approach in the practice of architecture or ideology. It is done by reducing the scale or making redefinition towards standard architectural elements. Ambiguity also frequently appears for example in the architecture form that assimilated yet contrasting with the surrounding environment context.

\section{Modern architecture in Singapore}

Modern architecture in Singapore were introduced by colonial architects in 1920s and 1930s that motivated by urban sanitation concerns. Innovations such as the "tropical-colonial" or "tropicalindigenous" styles were created in different tropical Asian contexts to address new life-styles and local environmental constraints. This architecture also known as "recent-past modernity" which also related to the nationalist spirit of a country.

The introduction of modern architecture in Singapore was done on a relatively large scale by the Singapore Improvement Trust (SIT). The first public housing projects by SIT started to use modern materials such as reinforced concrete, minimun decoration, and rationalized forms. Tiong Bahru was the first estate developed by SIT, where about
2000 units of three to five-story apartment buildings were built between 1936 and 1954. Other characters beside the building's elements are SIT adopted clean and rational architectural facades featuring rounded balconies, thin horizontal slabs, and ventilation holes that strenghten the modernist character.

In March 1960, soon after Singapore gained selfgovernment, the Housing Development Board (HDB) was established as a statutory body. It took over from SIT the pressing task of providing proper public housing for the entire population. In 1965, HDB managed to build 53.777 dwelling units where today $85 \%$ of Singapore population lives in HBD apartments. The design of apartments in singapore adresses several constrains such as land shortage, expanding population, and reasonable price. Moreover to tackle those constrains, HDB development in Singapore also put great emphasis on large-scale development of highrise, high density, low-cost, and standarized constructions.

One of the unique character of Singapore's architecture is the modern urban form that stands equally along the conservation of nature. Variation in building height, volume, and the way in which buildings are grouped together, are examples of how building form contributes to the unique character of spesific area. Orchard Road is a shopping podiums with high rise towers set further away fromthe road to give the sense of opennes. sThe tree-lined pedestrian mall now become the signature feature of Orchard Road. 


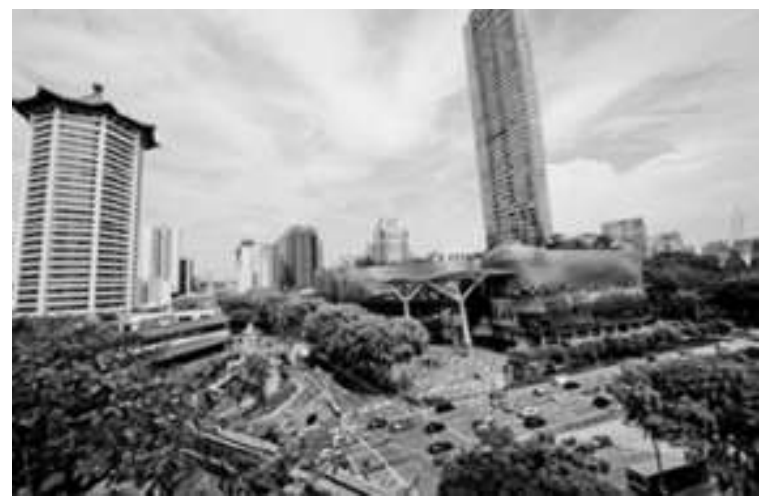

Fig.8 Buildings along Orchard Road, set back from the road street edge.

3. Discussion : The Comparison Between European and Asian Cities

The urban morphology of European Cities such as Rome and London is strongly influenced by the historical journey and the values of the monarchy system adopted. Oriented and in line with it, the system created a form of city that can accommodate the functions and roles of the center of royal activities. The circulation of the road network, the style of building to the activity of the inhabitants is highly dictated to seemingly ending the form of its active and passive mobility toward the center of royal or central government activity. Physical changes are evident in this phenomenon. Changes in the circulation of the road network that follow the main historic paths of the city to the emphasis of building style is very thick with historical nuances. This is quite contrary to cities in Asia such as Tokyo and Singapore. Both cities have special factors that affect the history of morphological changes of their respective cities, namely natural disaster factors and ethnic diversity factors. In addition, the values of life inherited from the culture of the kingdom and daily culture also affects some physical aspects of the city.

The circulatory system of cities in Europe is much more developed first to meet the growing needs of population movements. Typical characteristics can be seen from the diversity of modes and means of transportation in large numbers and also the innovation to meet the economic needs of the population. It has a positive impact on the circulation in the city center to reduce the occurrence of congestion. Meanwhile, cities in Asia such as Tokyo and Singapore are very diverse. Tokyo has a complex circular system with a concentric form, while Singapore has a grid form that classifies the rows of buildings with similar physical characteristics or called the phenomenon of "building forms".

The architectural superiority of the west turned out to be highly architectural in the Asian Cities. The emergence of a mixture of designs and structures from the west, quickly melt with local design and produce modern architectural styles, yet retain a slight characteristic of Asian cities. Tokyo still revives its architectural features mingled with western approaches, while Singapore really adopts the modern architectural style of the tropical area that also symbolizes diversity with records The city has limited physical extents.

\section{CONCLUSION}

Based on characteristic of urban morphological aspects on european and asian cities, we can conclude that there are several factors that influence the change in urban form of every cities from time to time. History, road patterns, and city's architecture shows how the cities transformed and shaped. European cities development were strongly influenced by the power of monarchy system government. London and Rome, for example, were shaped by a long history and fluctuated development. The ancients 
buildings also become the witness of how these cities has developed by thousand years. This is quite contrary to cities in Asia such as Tokyo and Singapore. Both cities have special factors that affect the history of morphological changes of their respective cities, namely natural disaster factors and ethnic diversity factors. In addition, the values of life inherited from the culture of the kingdom and daily culture also affects some physical aspects of the city. Based on the transportation or road patterns, Grid system is applied in European cities. Moreover, the circulatory system developed to fulfill the growing demands of people commute. Meanwhile Asian cities has a complex circular system with a concentric form. In the context of city's architecture, European cities are strongly influence by the Roman culture, where the buildings characterized by the domed roof, and building column. The emergence of a mixture of designs and structures from the west, quickly melt with local design and produce modern architectural styles, yet retain a slight characteristic of Asian cities.

\section{ACKNOWLEDGEMENT}

I would like to thank to my asisstants Ratih and Azka and also to my students of morphology class for preparing and supporting the data.

\section{REFERENCES}

Alasuutari, P. (1993). Laadullinen tutkimus (Qualitative Research). Tampere : Vastapaino

Conzen, M.R.G. (1960). Alnwick, Northumberland: A Study in Town-plan Analysis, Transactions and Papers (Institute of British Geographers), No.27: iii-122.
Larkham, P.J. (2002). Misusing 'Morphology', Urban Morphology, Vol.6, No.2: 95-96.

Yin, Robert K.(2003). Applications of Case Study Research, Sage, Thousand Oaks, CA, 2nd edition.

Foyle, Jonathan (2011). Hampton Court: The Lost Palace". BBC History. Archived from the original on 19 May 2011. Retrieved 16 June 2013.

Department of European Paintings. "Architecture in Renaissance Italy." In Heilbrunn Timeline of Art History. New York: The Metropolitan Museum of Art, 2000-.

Europe, R.S. 2014. Rome: Baroque Brilliance, Amerika Serikat. 25 Minute Britannica, E. 2010. Renaissance Architecture, New York, 4 Minute.

edX. 2015. The Meaning of Rome: The Renaissance and Baroque City | NotreDameX on edX | Course About Video , New York, 3 minute. 